\title{
Revista Complutense de Educación
}

ISSNe: 1988-2793

http://dx.doi.org/10.5209/rced.76131

\section{¿Cómo aprenden los docentes? Tránsitos entre cartografías, experiencias, corporeidades y afectos}

Autor: Hernández, H. H., Apraiz, E. A., Sancho, J. M., \& Gorospe, J. M. C. (Eds.).

Editorial: Octaedro.

Año de publicación: 2020

Número de páginas: 280

ISBN: 9788417667917

¿Cómo se aprende? ¿Cómo aprendemos los seres humanos? La pregunta se presenta valiente, visionaria, hacia una deseada respuesta que arrojaría luz al camino de cómo acceder al conocimiento.

Y es que es así como se presenta el libro publicado por Octaedro bajo un título que interroga, y que pone atención en la figura del docente, “¿Cómo aprenden los docentes? Tránsitos entre cartografías experiencias, corporeidades y afectos". La publicación recoge experiencias y reflexiones de una investigación realizada en el marco del Proyecto APREN-DO financiado por el Ministerio de Educación. El proyecto se nutre de las experiencias llevadas a cabo entre investigadores, y docentes de Educación Infantil, Primaria y Secundaria.

La pregunta presentada, de por si compleja, curiosamente redirecciona un foco tradicionalmente dirigido al alumnado. Y es que quizá ahí reside un matiz de una posible respuesta, en esa sugerencia que insinúa un aprender nunca resuelto y expansivo que afecta e impregna a todo aquel que este predispuesto a cuestionarse, sin que importe el lugar que ocupe. Se rompe así la premisa de unidireccionalidad entre aquel que enseña y el que aprende, la direccionalidad normativa de un uno absoluto que sabe y otro vulnerable que recibe desaparece.

Vuelvo a la pregunta, me coloco como docente frente a ella, la tentación de sumergirse en la lectura desvela un posicionamiento docente permeable, que requiere asumir un rol docente reflexivo, como un ser afortunadamente incompleto, con huecos para el cuestionamiento. Nos encontramos por lo tanto con un posicionamiento que aboga por un discente atento y en constante movimiento. Aquel que se pregunta está vivo y presente. Esa atmósfera se desprende de la lectura del libro que te transporta a un "y si..." incesante de eso que entendemos por ese binomio del acuerdo enseñar-aprender, entre la certidumbre e incertidumbre, siempre en transformación, desde un lugar que reivindica con urgencia comprender que la educación es latente y necesita ser constantemente repensada en un mundo convulso que es todo menos estático.

Ahí es donde se aloja uno de los intereses de este libro, cuando se descubre que paradójicamente no busca la respuesta a la pregunta, sino que se coloca en un lugar dónde convive con ella. No encontraremos recetas, ni una respuesta contundente, sino diversas aproximaciones sobre lo que cada uno puede llegar a desgranar en base a la pregunta en cuestión. La lectura fluye por lo tanto de un texto al otro, desde diversas aproximaciones, de posibilidades, de investigadores y docentes en relación con la comunidad educativa.

Este modo de vivir en relación al posicionamiento docente requiere aceptar lo incomodo como oportunidad, en lo incierto como opción personal que te sitúa en ese lugar tambaleante que permite abrir la puerta a nuevos modos de conocer. En ese sentido una de las resonancias que deriva de la lectura del libro reside en el Cómo se intenta abordar la pregunta. Lo no lineal del relato, los quiebros que cuestionan e insinúan nuevas cuestiones sin miedo, imprimen una sensación de construcción del conocimiento con el profesorado y no desde este. Esto genera un entramado de acercarse al conocimiento que busca construirse en relación, dando cuenta del propio proceso investigador en educación que debe de ser atendido, un posicionamiento onto-epistemológico de lo que puede significar aprender en relación al otro en el propio marco de la investigación. Por lo tanto, su interés no reside tan solo recoger esos relatos de los docentes sino que, se compromete y se entiende el propio modo en el que se construye esa relación permitiéndose avanzar por todo aquello por lo que nos sentimos afectados en la propia investigación.

En esta línea cabe suponer que las respuestas no se presentan certeras, y se muestran alejadas de respuestas contundentes de lo que puede ser o no aprender. Los textos abogan por un lugar desde el que se puede hacer, unos mimbres que permitan plantear un modo de pensar elástico que posibilite entrar en relación sobre los supuestos del aprender.

Para que esto suceda la metodología llevada a cabo en las diferentes experiencias que se recogen en el libro intuye un modo de reflexión expansivo, alejado de modos de acercarse a conocimientos estancos habitualmente centrados en lo textual. Desde la creencia de que los modos de acceder al conocimiento y por ende los de aprender son inabar- 
cables, la investigación es atrevida y se expone a la incertidumbre de lo que pueda suceder, quizá a lo desconocido que propicia el devenir y apuesta por métodos visuales que propicien otros modos de narrativas.

Alejarse de modo de repensarnos establecido propicia que emerjan nuevas oportunidades, nuevos diálogos, nuevas interacciones... nuevo. Nuevo inevitable, por cuanto que toda puerta desconocida no se sabe lo que contendrá detrás.

Desde esta incertidumbre sugerente de girar el pomo de la puerta vuelvo a acercarme a la pregunta y me atrevo a decir que detrás esperan nuevas preguntas e incógnitas que nos lleven a repreguntarnos ¿Como aprendemos los docentes? Si, la necesidad de esta reformulación sucede, será que el texto nos invita a colocarnos en un lugar que posibilite repensarnos sin cesar.

Miriam Peña Zabala

Universidad del País Vasco UPV/EHU

Miriam.pena@ehu.eus 